\title{
Blended Learning as a Theoretical Framework for the Application of Podcasting
}

\author{
Kuang-yun Ting ${ }^{1}$ \\ ${ }^{1}$ Department of Applied English, St. John's University, Taiwan \\ Correspondence: Kuang-yun Ting, Department of Applied English, St. John's University, Taiwan. E-mail: \\ sandrine@mail.sju.edu.tw
}

Received: February 24, 2014 Accepted: March 30, 2014 Online Published: April 14, 2014

doi:10.5539/elt.v7n5p128 URL: http://dx.doi.org/10.5539/elt.v7n5p128

\begin{abstract}
The use of podcasting has attracted the attention of teachers because it is content-rich and is of wide general interest. Users can listen to podcasts via the Internet or download them on to a portable music player. Some also offer video or animation to make the contents more interesting and easier to understand. Accordingly, podcasts that tend to focus on the use of vocabulary can be very effective in language learning. They help learners hear how to pronounce their words clearly and use them appropriately. In addition to the benefit of its multimodal facilities, the main advantage of podcasting lies in the variety and the control it provides. Many podcasts provide an authentic context including those which are vocationally orientated. In other words, learners can access podcasts linked to their field of study or interest. Therefore, this research project explores how podcasts in an ESL (English for specific purposes) environment can be used with foreign language learners. It then discusses learners' perspectives of podcasts related to certain subjects. Finally, it proposes a number of suggestions for practical strategies and techniques for teaching English through podcasting.
\end{abstract}

Keywords: podcasting, multimodal facilities, action research

\section{Introduction}

Podcasting is a portmanteau word based on iPod and broadcasting and means the diffusion of audio via the Internet. It involves making digital recordings of radio programmes. A podcast is a radio programme or visual clip that is stored in a digital form. The methods for downloading podcasts are different from other downloading methods. For example, if users want to listen to a programme called " 6 minute English" from the BBC, they can access it regularly on-line for updates. Alternatively, they can subscribe so as to receive future episodes via their $\mathrm{mp} 3$ player when available. A tool called a pod-catcher such as iTunes, acts as an intermediary to download the updated programme. Users can download it to a portable device such as an iPod or mp3 player and listen to it later or watch it as many times as they want. Podcasting has grown exponentially since its introduction. Visual information including still images, animation or video placed on the Web is available as video podcasts.

A podcast containing several topics usually includes a series of audio files for users to listen to on the Internet or to download to portable media players. The function of portable podcasts supports the concepts of learning on demand (Islam, 2007). Some podcasts also offer video or animation which increases the effectiveness of computer assisted language teaching. The variety of the podcasts on the Internet ensures that language learners can have access to valuable listening resources so as to practise at their own pace outside the classroom. This is the reason why podcasting has recently become popular.

However, the availability of rich teaching resources does not necessarily equal an enhanced learning opportunity (Wiebe \& Kabata, 2010). Teachers need to know more about how students use podcasts as a tool for language learning. The emphasis should be on the evaluation of the learning output according to the various ways in which language material is presented and used. This project explores learners' reaction to their initial experience of using podcasting and what progress they expected to make in learning the target language through this medium.

\section{Literature Review}

\subsection{Podcasting}

Podcasting is being used to support learning in higher education (Lee, McLoughlin, \& Chan, 2008; Maikat, Martinez, \& Jorstad, 2007). There are four principal models for its use in some UK universities, it can be: 
teaching-driven, service-driven, marketing-driven or technology-driven models (Harris \& Park, 2008) and it is now considered to be a technology-enhanced teaching strategy. One of the most promising features characteristics offered by podcasting is its audio content syndication which means audio content is automatically distributed over the web. Accordingly, some researchers advocate using audio podcasts for learning listening and integrate them with e-learning models (Cebeci \& Tekdal, 2006). Furthermore, educators have designed lecture materials in audio and video podcast form to facilitate the comprehension of lectures. The usefulness of the audio or video podcasts is rated highly because students can preview or review the lesson at their own pace (Copley, 2007). Interestingly, students state that they do not attend lectures less because of the availability of podcast material. They still value highly the interaction with teachers and classmates in lectures. Interaction is an important aspect of introducing podcasting in lessons (Lee \& Chan, 2006).

In the field of second language learning, a number of studies have explored ways in which podcasting can be utilised. They either present those available on the Internet or show how they can be useful for listening and speaking practice (Chinnery, 2006; Dudeney \& Hockly, 2007; Rosell-Aguilar, 2007). An evaluation of learners' perceptions towards podcasting and their expectations has not yet been undertaken, which should be considered in choosing to use podcasts in classroom.

\subsection{Blended Learning}

Blended learning means a combination of face-to-face classroom instruction integrated with online components. It provides learners a place to practice the target language with authentic material (Garrison \& Vaughan, 2008). The application of blended learning has become more prominent in second language classrooms as it combines traditional learning with online internet applications (MacDonald, 2008). Teachers actually gain more instructional experience with the approaches. Blended learning usually employs a wide variety of media and materials as well as different teaching methods and assessment tools (Sharma \& Barrett, 2007). In other words, blended learning offers more choices in learning and a faster supply of knowledge and information. Thus, students are expected to be motivated by blended learning, and eventually, to realize their learning objectives. Accordingly, this study adopts the use of podcasts to provide the students a blended learning experience.

\section{Research Methodology}

\subsection{Research Stance}

The focus of the inquiry in this study is to explore learners' perspective of the use of podcasts to enhance English learning. More explicitly, this inquiry was conducted for the express purpose of helping understand the application of podcasting in teaching. Accordingly, the project involves the mixing of quantitative and qualitative methods to seek solutions to focus on the use of podcasts (Creswell \& Clark, 2011). The most important aspect of this research is to help teachers exam their instructional practices based on their own situations. At the same time, the practice is expected to offer other teachers more examples to improve teaching practice.

\subsection{Participating Students}

The twenty-nine participants in the study were English majors attending evening classes at a university of science and technology and were working in different companies during the day. Some of them had even acquired a first or a master's degree in a different discipline, e.g., business, educational leadership, human resources and electronic engineering. Their motivation to take extra English courses came from job requirements and their desire for self-improvement. In other words, most students had a specific motivation for learning English. This was the main reason why these students were chosen as research participants. Positive learners can offer valuable feedback and comments to improve a teacher's application of technology in the classroom.

\subsection{Course Design}

The course context for the study was "Computer Assisted Language Learning", and the class met two hours a week. It mainly introduced and explored current applications in CALL including websites, online software and podcasts for language learners. Podcasting was used for six weeks from week 12 to week 17 . The whole process is described here in three stages. During stage one (week 12), the concept of podcasting was explained to the students. There were briefed about podcasts: what they were and how they were going to be used in learning. Most students were totally new to the medium although many of them had mp3 players. Several podcasts, based on English language teaching material, were then introduced. For example, Just Vocabulary (http://www.justvocabulary.libsyn.com/) is for students who want to practise GRE test, ESL podcast (http://www.eslpod.com/website/) which offers a variety of specific topics such as Health, Entertainment, English Café, Business, Transportation, Relationships and Travel for English learners. In addition, the website, Podcast Directory (http://www.podcastdirectory.com/) was recommended for students wishing to search for 
their own podcasting site.

Stage two lasted four weeks (week 13-week16) and involved the use of actual podcast materials. The project was conducted using a task-based approach in order to enhance learning opportunities for self-directed learners. Students were free to choose a podcast for themselves for one month. The idea was to motivate learners to practise their English skills in a self-directed manner. In week 16, each student introduced a chosen podcast based on the content, technical design, the length of each topic and the potential for language learning purposes.

Stage three consisted of a relevant questionnaire and a reflection assignment on how the use of podcasts contributed to learning. As mentioned before, most students in this class had different jobs in the daytime. Accordingly, they were encouraged to select a podcast which was related to their job or produced by their companies. In this way, it was expected that podcasts would be more beneficial to learning.

\subsection{Data Analysis}

Both qualitative and quantitative data were collected. The survey with ten questions was expected to indicate general perceptions of the podcasts and their utility in the language learning process. The questions focused on their approach to listening - the time they spent listening to podcasts, the importance of the transcript, and their expectations. There was also a space for learners to explain their reasons for choosing specific answers.

The students' final reflective assignment provided valuable qualitative data tabulated in descriptive categories. Their comments were used for both analysis and presentation in order to show whether they confirmed or differed from the theories mentioned in the literature review section and to provide new insights into their validity. There was a follow-up interview, after the submission of the assignment and the questionnaire to clarify any ambiguity in the students' written reflections and/or in their responses to the questionnaire.

\section{Results and Discussion}

The qualitative and quantitative data analysed, based on student views on the podcasts chosen, falls into three categories: 1) their type 2) their value for learning English skills and 3) their design.

\subsection{The Type of Podcast Chosen}

The podcasts chosen by students included a variety of subjects, e.g., business, news, language journal, vocabulary, literature and specific organisation. The theme and podcast titles listed below as well as student reasons for their choice (Table 1).

Table 1 . The categories of podcasts chosen by students

\begin{tabular}{llll}
\hline Theme & Podcast title & Indicators & $\begin{array}{c}\text { Student's } \\
\text { Numbers }\end{array}$ \\
\hline Business English & Business English Pod & Subject oriented & 1 \\
News English & BBC, CNN & A variety of updated issues & 5 \\
Language journal & Studio classroom & Instructor's role & 3 \\
Vocabulary, Lexical use & Just Vocabulary, Word Nerds & Words and phrases learning & 5 \\
Literature & Penguin group, Wired for books & Audiobooks & 5 \\
ESL learners & ESL podcast, Listen-to-English, & Well-organised content for English & 7 \\
\multirow{2}{*}{ Specific organisation } & ESL Podcards & learners & 3 \\
& National Geographic, NASA & Specific interest & 29 \\
\hline Total & podcasting, C21 Real Estate & & 29 \\
\hline
\end{tabular}

The above podcasts can be classified into two main groups. First, authentic content read by native speakers such as the news in English (BBC, CNN), literature (Penguin group, Wired for books) and topics based on specific organisations (National Geographic, NASA, C21 Real Estate). Participants who chose these podcasts wanted to consult specific themes or access a variety of topics. Here are examples: 


\subsubsection{Authentic Content Read by Native Speakers}

It provides a wide range of programmes. (BBC)

With a global view point and numerous professionals reporting on world news and with on-the-scene reports it keeps me informed in a very effective way. The great thing is there are many choices-technology, sports, travel, Asia, US, etc. (CNN)

\subsubsection{Topics Based on Specific Organisations}

I love reading astronomy-related stories. This website introduces lots of NASA activities and offers pictures. It is very interesting to keep on exploring it. (NASA)

I like C21 Real Estate because this podcast relates to my daily work. I hope to use it at work. When foreigners come to ask me about properties, I often don't know how to provide them with information. So I hope to get information about real estate buying and selling tactics via this podcast. (C21 Real Estate)

Second, language content specifically designed for English as a second language learner including a language journal (Studio classroom), vocabulary (Just Vocabulary, Word Nerds) and specific topics (Business English Pod, ESL podcast, Listen-to-English, ESL Podcards). Obviously, students who chose this type of podcast focused on English vocabulary or grammatical structure learning.

The content of the podcast is clearly organised. (Business English Pod)

These kinds of podcast help me learn more systematically. (Just Vocabulary)

Some topics in this podcast have grammar and vocabulary which I do not know.

The podcast has a dictionary function. People can check the meaning of a word by clicking underlined word. (Listen-to-English)

\subsubsection{The Content of Podcast}

In addition, participants' opinions on the content of chosen podcasts can be divided into two categories: a variety of accents and authentic text. The following statements are typical examples.

A variety of accents

I can hear different accents. (BBC)

I chose a podcast with a New York accent. The content was about Paris Hilton's biography. So, I can learn about some famous people's background and enhance my listening ability. (ESL Podcards)

The speaker has a British accent that is very elegant. (Listen-to-English)

The above statements suggest that learners have a better motivation when they are exposed to the new language with different accents.

\subsubsection{Authentic Text}

I learned a lot by listening to these audio files. They gave me brief introductions to famous cities as well as some famous people's biographies, including Sean Connery, Nicole Kidman, U2 (a popular music group). (ESL Podcards)

The podcast helps us increase our knowledge of geography which can stimulate our conversation topics within world, cultural, historical, and natural contexts. (National Geographic)

The views expressed indicate that the lives of celebrities or a general introduction to English speaking countries are more attractive to learners. This kind of context can be both realistic and interesting. The issue of authentic input is emphasised here because authentic language provides input that is rich enough for second language acquisition to occur (Tschirner, 2001). Accordingly, learners can appreciate that learning takes place when they have a sense of achievement. The finding such as the importance of authentic materials to language learners is in accordance with Donnelly and Berge's (2006) study.

4.2 The Value of Learning English Skills

As can be seen in Table 2, podcasts provide a useful platform for learning purposes. 
Table 2. The correlation between the use of podcasts and the enhancement of English skills

Question 9- Did accessing podcasts enhance your English skills?

$\mathrm{N}$-number, \%=percentage

Degree of usefulness

\begin{tabular}{|c|c|c|c|c|c|c|c|c|c|}
\hline \multicolumn{2}{|c|}{$100 \%-80 \%$} & \multicolumn{2}{|c|}{$80 \%-60 \%$} & \multicolumn{2}{|c|}{$60 \%-40 \%$} & \multicolumn{2}{|c|}{$40 \%-20 \%$} & \multicolumn{2}{|c|}{$20 \%-0 \%$} \\
\hline $\mathrm{N}$ & $\%$ & $\mathrm{~N}$ & $\%$ & $\mathrm{~N}$ & $\%$ & $\mathrm{~N}$ & $\%$ & $\mathrm{~N}$ & $\%$ \\
\hline 9 & $31 \%$ & 10 & $34.5 \%$ & 8 & $27.6 \%$ & 1 & $3.4 \%$ & 1 & $3.4 \%$ \\
\hline
\end{tabular}

It is not surprising that most students agreed that the podcast is the most beneficial tool for listening practice. Except from listening skills, reading skill, grammar and vocabulary acquisition were mentioned most by the participants. Two students stated that podcasts also help speaking and writing because they could use sentences from the podcasts in their jobs.

This research focused on learners' perceptions of language practice with novel technology and improved any specific language skill. There is an assumption that skills improve in relation to how often students practise usage both in class and outside of class. If language skills are to be improved, the teaching process should ensure that maximum use is made of the students' environment. Take listening as an example. Teachers should create tasks which allow students to contextualise what they are listening to. Thus podcasting is introduced because an $\mathrm{mp} 3$ player has become the learners' favoured technology and therefore linked to their motivation to study. In brief, developing students' ability to become more independent learners was addressed in the research project. As a whole, students appreciated the opportunity to work with new digital technology and showed that they enjoyed learning English with podcasts.

\subsubsection{The Reflection of Using Podcasts}

The $B B C$ podcast provides many ways to listen to the content. We can listen to programmes through radio, the Internet, digital TV and mobile phone. It is really awesome! (BBC)

I am looking for methods to improve my listening comprehension. Fortunately, it (podcasts) offers me a good chance. (Business Podcast)

CNN podcast is the best I have ever listened to. I like to listen to the news. I think CNN is good and especially the hourly update. (CNN)

Podcasts help me learn and listen to English while I wait for train. I could use my time for learning English without feeling under any pressure. (CNN)

I can subscribe to podcast by email which means I can receive regular email with new content. It makes my study more convenient. (Just Vocabulary)

Wired for Books collected many easy-to-understand books, such as The Wonderful Wizard of $\boldsymbol{O}$ z. The player not only read the story, but their intonation makes audiences very comfortable. I like audio books. The beautiful sound makes me feel as a child with infinite imagination. I will keep listening to the content. (Wired for books)

From "Checkers Speech", I learned how to say "it is wrong to do something if this is the case". I think this sentence is useful in my job. Sometimes I am doing the right thing but my customers do not think so. In that situation I can say to my customers, I or my company was wrong if we did so and so. (Word Nerds)

As noted above, students enjoyed practising English skills using podcasts. In working with podcasts, students' negative attitudes and anxieties were lessened or removed. More specifically, through use of podcasting, students were given many more opportunities to practise the target language, not only in class, but outside classroom as well. Accordingly, podcasts is regarded as an enormously valuable learning tool (Evans, 2008).

\subsection{Podcast Design}

Audio was definitely considered of great importance by most participants and video design came next. Further, a transcript of the podcast content was regarded as a fairly important necessity. 
Table 3. The importance of transcript

Question 4- Do you think that a transcript of the podcast is important?

$\mathrm{N}$-number, $\%=$ percentage

Degree of usefulness

\begin{tabular}{|c|c|c|c|c|c|c|c|c|c|}
\hline \multicolumn{2}{|c|}{$100 \%-80 \%$} & \multicolumn{2}{|c|}{$80 \%-60 \%$} & \multicolumn{2}{|c|}{$60 \%-40 \%$} & \multicolumn{2}{|c|}{$40 \%-20 \%$} & \multicolumn{2}{|c|}{$20 \%-0 \%$} \\
\hline $\mathrm{N}$ & $\%$ & $\mathrm{~N}$ & $\%$ & $\mathrm{~N}$ & $\%$ & $\mathrm{~N}$ & $\%$ & $\mathrm{~N}$ & $\%$ \\
\hline 17 & $58.6 \%$ & 6 & $20.7 \%$ & 4 & $13.8 \%$ & 2 & $6.9 \%$ & 0 & $0 \%$ \\
\hline
\end{tabular}

The majority of the participants pointed out that a transcript highly was a very important resource for them. A podcast which had audio transcripts was generally evaluated as a good podcast by many participants. Typical examples of statements by students are the following.

\subsubsection{The Benefit of a Transcript}

It only offers a partial transcript of the first or second paragraph. I think it doesn't help learners. (Business Podcast)

Although I don't read the transcript while listening to the podcast, I still think the transcript of the podcast makes good reading material. It is very clear, useful and well-organised just like an abstract from Wikipedia. (ESL Podcards)

However, I could understand the whole report most of the time. I hope the podcast provides a transcript to read. It will be very helpful. (ESL podcast)

There is a transcript when you listen to the article. I think it is very important for me to listen and to understand. (Listen-to-English)

When the podcast updates, the whole transcript is also updated, so learners can learn more skills such as vocabulary, reading and of course listening. (NASA Podcasting)

\section{It is important because it can help me understand what I am listening to. (Studio classroom)}

The above statements, in which the word "understand" occurs frequently, confirm the importance attached, by learners to transcripts in the learning experience. There is an argument that transcripts may distract learners from listening practise and they turn to practise reading. However, the point is that learners should be given relevant information when they are requested to comprehend a specific topic. For example, non-native learners are able to interpret a dialogue taking place in a restaurant because they have a certain background knowledge relating to restaurant English. In other words, comprehension will be difficult if learners lack culturally or subject specific scripts (Richards, 1983). Most learners do not have real-world experience in target countries so they are unable to understand many of the utterances. Therefore, transcripts are necessary for language learners because they can make subject matter more comprehensible and then trigger specific interest in learners (Lynch, 2007). If teachers are worried about the issue of developing listening skills, they should use transcripts in pre-listening activities.

\section{Conclusions}

This paper has introduced a blended learning approach, an innovative and exciting way, for students to practise their language skills and has presented a learners' perspective of podcasting. Blended learning has "the potential to transform student-learning experiences and outcomes" (Davis \& Fill, 2007, p. 817). It means that a blended learning approach focuses on learners instead of instructors which have significant impact to student's learning experience. Employing podcasting in learning motivates learners to apply a wide range of strategies to comprehend authentic topics at their own pace and under conditions free from anxiety. The novelty and diversity of podcasts is expected to prompt learners to perfect either language acquisition or skills. Learners' reflections also indicate that participants found that transcripts were useful for understanding the podcast, thereby motivating students to practise more. Transcripts are therefore an aid to student motivation as well as comprehension.

\subsection{Reflecting on Teaching Practice}

This paper proposes a number of suggestions for practical strategies and techniques for teaching English through the medium of podcasting. First, students have to be given a lot of guidance before they start surfing for podcasts. In this project, the teacher explained the function of podcasting and introduced a podcasting directory. Some 
students were still confused about how to use podcasts. It seems that teachers should not only provide examples for students but also ask them to demonstrate the use of podcasting in future classes. In this way, all students will have a better concept of the purpose and value of podcasts in the language learning context.

Second, podcasts chosen by students or recommended by teachers should be reviewed carefully before being adopted-some, for example, may be interesting and creative but they may not help students enhance their language learning or to increase their chances of practising the target language. The podcast, C21 Real Estate, is an example. The learner who chose it expected to get more information about selling and buying tactics used in the Real Estate business. However, this podcast is seldom updated and is not friendly to users. Accordingly, learners will not find it useful or easy to use.

In brief, the evaluation of technology assisted language learning and classroom activities is always an important issue because instructors will have a better understanding and knowledge of how digital technology can be used for specific learners for confident learning (Son, 2007; Stepp-Greany, 2002).

The last important issue is that the optimum level of English proficiency for students to take full linguistic advantage of podcasting is pre-intermediate. The directory of podcasts and most of the podcasts are in English. It is only when learners have a sufficient linguistic background that they are able to follow instructions and make use of the medium.

\subsection{Recommendations for Further Practice}

The podcast application in this study can be a reference by teachers who are interested in applying technology in the English classroom. The great benefit provided by podcasts is their authenticity. Teachers; therefore, need to manage different types of podcasts for students' diverse learning needs. First, teachers can encourage students to produce a radio show as a project choice.

The class members and the teachers are no longer the main audiences. When students upload their radio show on the World Wide Web, they reach a wider audience. Second, teachers have to be aware it is not that easy for students to record a show in English. Students need clear guidelines to prepare and understand that the process could potentially be difficult. Accordingly, they should keep their planned content which is brief, simple and understandable. Finally, the students can invite their family and friends to listen to it and make comments. In this way, they have a real audience for their show which can serve a great motivator. In addition, teachers who are interested in online application can use a reflective approach to promote their professional development. By observing, teachers can reflect continuously on their instructions and decide upon their effectiveness. If necessary their instructions can be changed or improved.

\section{References}

Cebeci, Z., \& Tekdal, M. (2006). Using podcasts as audio learning objects. Interdisciplinary Journal of knowledge and Learning Objects, 2(1), 47-54.

Chinnery, G. (2006). Emerging Technologies going to the MALL: Mobile Assisted Language Learning. Language Learning \& Technology, 10(1), 9-16.

Copley, J. (2007). Audio and video podcasts of lectures for campus-based students: Production and evaluation of student use. Innovations in Education and Teaching International, 44(4), 387-399. http://dx.doi.org/10.1080/14703290701602805

Creswell, J. W., \& Clark, V. L. P. (2011). Designing and conducting mixed methods research (2nd ed.). Thousand Oaks, CA: Sage.

Davis, H. C., \& Fill, K. (2007). Embedding blended learning in a university's teaching culture: Experiences and reflections. British Journal of Educational Technology, 38(5), 817-828. http://dx.doi.org/10.1111/j.1467-8535.2007.00756.x

Donnelly, K. M., \& Berge, Z. L. (2006). Podcasting: Co-opting MP3 Players for Education and Training Purposes. Online Journal of Distance Learning Administration, 9(3).

Dudeney, G., \& Hockly, N. (2007). How to teach English with technology. England: Pearson Education Limited.

Evans, C. (2008). The effectiveness of m-learning in the form of podcast revision lectures in higher education. Computers and Education, 50(2), 491-498. http://dx.doi.org/10.1016/j.compedu.2007.09.016

Garrison, D. R., \& Vaughan, N. (2008). Blended Learning in Higher Education: Framework, Principles, and Guidelines. San Francisco: Wiley.

Harris, H., \& Park, S. (2008). Educational usages of podcasting. British Journal of Educational Technology, 
39(3), 548-551. http://dx.doi.org/10.1111/j.1467-8535.2007.00788.x

Islam, K. (1007). Podcasting 101 for Training and Development. San Francisco: John Wiley \& Sons.

Lee, M. J. W., \& Chan, A. (2006). Exploring the Potential of Podcasting to Deliver Mobile Ubiquitous Learning in Higher Education. Journal of Computing in Higher Education, 18(1), 94-115. http://dx.doi.org/10.1007/BF03032726

Lee, M., McLoughlin, C., \& Chan, A. (2008). Talk the talk: Learner-generated podcasts as catalysts for knowledge creation. British Journal of Educational Technology, 39(3), 501-521. http://dx.doi.org/10.1111/j.1467-8535.2007.00746.x

Lynch, T. (2007). Learning from the transcripts of an oral communication task. ELT Journal, 61(4), 311-319. http://dx.doi.org/10.1093/elt/ccm050

MacDonald, J. (2008). Blended learning and online tutoring: Planning learner support and activity design (2nd ed.). Burlington: Gower Publishing Company.

Maikat, R. P., Martinez, R. D., \& Jorstad, J. A. (2007). Podcasting for your class. The Journal of Physical Education, Recreation \& Dance, 78(5), 14-16. http://dx.doi.org/10.1080/07303084.2007.10598016

Richards, J. C. (1983). Listening Comprehension: Approach, Design, Procedure. TESOL Quarterly, 17(2), 219-240. http://dx.doi.org/10.2307/3586651

Rosell-Aguilar, F. (2007). Top of the Pods - In Search of a Podcasting "Podagogy" for Language Learning. Computer Assisted Language Learning, 20(5), 471-492. http://dx.doi.org/10.1080/09588220701746047

Sharma, P., \& Barrett, B. (2007). Blended Learning: Using technology in and beyond the language classroom. Oxford: Macmillan.

Stepp-Greany, J. (2002). Student perceptions on language learning in a technological environment: Implications for the new millennium. Language Learning \& Technology, 6(1), 165-180.

Son, J. (2007). Learner Experiences in Web-based Language Learning. Computer Assisted Language Learning, 27(1), 21-36. http://dx.doi.org/10.1080/09588220601118495

Tschirner, E. (2001). Language Acquisition in the Classroom: The Role of Digital Video. Computer Assisted Language Learning, 14(3-4), 305-319. http://dx.doi.org/10.1076/call.14.3.305.5796

Wiebea, G., \& Kabata, K. (2010). Students' and instructors' attitudes toward the use of CALL in foreign language teaching and learning. Computer Assisted Language Learning, 23(3), 221-234. http://dx.doi.org/10.1080/09588221.2010.486577

\section{Copyrights}

Copyright for this article is retained by the author(s), with first publication rights granted to the journal.

This is an open-access article distributed under the terms and conditions of the Creative Commons Attribution license (http://creativecommons.org/licenses/by/3.0/). 